\title{
Preserved Vasoconstriction and Relaxation of Saphenous Vein Grafts Obtained by a No-Touch Technique for Coronary Artery Bypass Grafting
}

\author{
Toshiyuki Yamada, MD; Takeshi Adachi, MD, PhD; Yasuo Ido, MD, PhD; \\ Nobuyuki Masaki, MD, PhD; Takumi Toya, MD; Tomoya Uchimuro, MD; \\ Kosaku Nishigawa, MD; Hisao Suda, MD, PhD; Motohiko Osako, MD, PhD; \\ Masataka Yamazaki, MD, PhD; Shuichiro Takanashi, MD, PhD; Hideyuki Shimizu, MD, PhD
}

Background: To obtain a saphenous vein graft (SVG) for coronary artery bypass grafting (CABG), the benefit of using a no-touch (NT) technique in vascular function has not been fully investigated.

Methods and Results: The pathological and physiological functions of human SVGs with a NT technique to preserve the perivascular adipose tissue (PVAT) and ones obtained by using a conventional (CON) technique removing PVAT, were examined. Immunohistochemistry of the section of SVGs showed that the phosphorylation of endothelial nitric oxide synthase in the endothelium of the NT group was more responsive to vascular endothelial growth factor. A myograph of SVGs showed greater contraction with phenylephrine in the NT group. However, the strong contraction was eliminated in SVGs taken by electrocautery. In the 10 patients whose SVGs were taken without electrocautery, endothelial-dependent relaxation with bradykinin was apparently increased in the CON group more than in the NT group. Smooth muscle relaxation with nitroprusside was higher in the CON group at the lower concentrations; however, the relaxation became greater in the NT group at the high concentrations. Therefore, the effect of neutralizing PVAT-released factors in the both groups was further examined. After medium of NT and CON were exchanged in half, relaxation of SVGs was immediately restored in the NT group.

Conclusions: The results suggest that the NT technique preserves the functions of vasoconstriction and relaxation. Also, the presence of PVAT-released vasoconstrictive factors was suspected.

Key Words: Coronary artery bypass grafting; Nitric oxide; No-touch technique; Perivascular adipose tissue; Saphenous vein graft

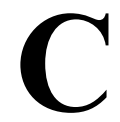
oronary artery bypass grafting $(\mathrm{CABG})$ for ischemic heart disease is a major surgical procedure, and approximately 50 years have passed since CABG using a saphenous vein graft (SVG) was first reported. ${ }^{1}$ Nevertheless, these grafts are still widely used because of their several advantages, including ease of access, ease of operation, sufficiency of length for transplantation, and short harvest time.

In the conventional (CON) technique, SVG is harvested by removing perivascular adipose tissue (PVAT), and subsequently expanding it by saline and high pressure. These processes are intended to secure graft flow. Nonetheless, the CON SVGs have low patency rates and poor clinical outcomes relative to arterial grafts. ${ }^{2-5}$ Damage of
SVGs from the procedures has been suspected. ${ }^{6}$ A no-touch (NT) technique preserving PVAT to minimize the damage of SVGs at the time of collection was reported 20 years ago. ${ }^{7}$ Clinical and histological data have been accumulated until now. ${ }^{8-11} \mathrm{~A}$ study of the longest observation showed that patency of SVGs using the NT technique was comparable with that of thoracic artery grafts after 16 years. ${ }^{12}$

However, the physiological function of SVGs before use for CABG has not been fully investigated so far. The study was sought to compare SVGs collected by using either the $\mathrm{CON}$ or NT techniques and a myograph. We hypnotized that the technique for harvesting SVGs could affect the functions of grafts associated with durability.

Received June 25, 2018; revised manuscript received September 15, 2018; accepted October 9, 2018; J-STAGE Advance Publication released online November 3, 2018 Time for primary review: 22 days

Department of Cardiovascular Surgery, Keio University Graduate School of Medicine, Tokyo (T.Y., M.Y., H. Shimizu); Department of Cardiovascular Surgery, National Hospital Organization Tokyo Medical Center, Tokyo (T.Y., M.O.); Department of Internal Medicine, Division of Cardiovascular Medicine, National Defense Medical College, Tokorozawa (T.A., Y.I., N.M., T.T.); Department of Cardiovascular Surgery, Sakakibara Heart Institute, Fuchu (T.U., K.N., M.Y., S.T.); and Department of Cardiovascular Surgery, Nagoya City University, Nagoya (H. Suda), Japan

Mailing address: Takeshi Adachi, MD, PhD, Department of Internal Medicine, Division of Cardiovascular Medicine, National Defense Medical College, 3-2 Namiki, Tokorozawa 359-8513, Japan. E-mail: tadachi@ndmc.ac.jp

ISSN-1346-9843 All rights are reserved to the Japanese Circulation Society. For permissions, please e-mail: cj@j-circ.or.jp 


\section{Methods}

Human tissues were used in this experimental study, and written informed consent was obtained from all the patients. The research was also reviewed and approved by the respective Ethics Committees of Keio University Hospital (20160070), Sakakibara Heart Institute (16-058), and the National Defense Medical College (2657). This study was conducted in accordance with the principles of the Helsinki Declaration and its later amendments.

\section{Patient Selection and Harvesting Vein Segments}

We enrolled patients who underwent elective CABG and used SVGs collected using the NT technique. ${ }^{21}$ Only surplus SVG tissue that was not used for surgery was used in the experiments. To minimize endothelial damage, the extracted segments were not expanded with saline, as in the CON method. SVG tissue from each patient was divided into 2 groups of 3-mm segments: an NT group with PVAT retained and a CON group with PVAT removed. The images of SVGs are shown in Figure S1. Thereafter, each segment was placed in heparinized blood taken from completely heparinized patients, as soon as possible after harvesting.

\section{Immunohistochemistry (IHC)}

IHC was performed on the NT and CON samples, which were added to Krebs-Henseleit solution $(116 \mathrm{mmol} / \mathrm{L}$ $\mathrm{NaCl}, 4.7 \mathrm{mmol} / \mathrm{L} \mathrm{KCl}, 1.2 \mathrm{mmol} / \mathrm{L} \mathrm{MgSO}_{4}, 25 \mathrm{mmol} / \mathrm{L}$ $\mathrm{NaHCO}_{3}, 1.2 \mathrm{mmol} / \mathrm{L} \mathrm{KH} 2 \mathrm{PO}_{4}, 5.5 \mathrm{mmol} / \mathrm{L}$ D-glucose, $2.5 \mathrm{mmol} / \mathrm{L} \mathrm{CaCl}_{2}$ ) and incubated for $2 \mathrm{~h}$ to exclude blood components. Samples were then divided into 3 groups: (1) in group 1, the samples were fixed in formalin as soon as possible; (2) in group 2, the samples were fixed in formalin after $2 \mathrm{~h}$ of incubation; and (3) in group 3, the samples were fixed in formalin by reacting with vascular endothelial growth factor (VEGF) $(20 \mathrm{ng} / \mathrm{mL})$ for $5,15,30$, and $60 \mathrm{~min}$ (labeled the V5, V15, V30, and V60 groups respectively).

Formalin-fixed SVGs were embedded in paraffin, and for IHC, it was washed with xylene, 100\% ethanol, 95\% ethanol, and water for slide deparaffinization. Proteolytic enzyme treatment was not performed, but endogenous peroxidase was removed by treatment with $3 \% \mathrm{H}_{2} \mathrm{O}_{2}$ for $5 \mathrm{~min}$ and washing it under running water for $5 \mathrm{~min}$. Antigen retrieval was performed by using the autoclave method $\left(20 \mathrm{~min}\right.$ at $\left.121^{\circ} \mathrm{C}\right)$ and a citrate buffer $(10 \mathrm{mmol} / \mathrm{L}, \mathrm{pH} 8)$. After cooling, the plate was washed with phosphatebuffered saline $(1.37 \mathrm{~mol} / \mathrm{L} \mathrm{NaCl}, 27 \mathrm{mmol} / \mathrm{L} \mathrm{KCl}$, $\left.81 \mathrm{mmol} / \mathrm{L} \mathrm{Na}_{2} \mathrm{HPO}_{4}, 12 \mathrm{H}_{2} \mathrm{O}, 14.7 \mathrm{mmol} / \mathrm{L} \mathrm{KH}_{2} \mathrm{PO}_{4}\right)$ and blocking was performed for $60 \mathrm{~min}$ using Blocking One (1/5, Nacalai Tesque). To investigate the difference in nitric oxide synthesis between NT and CON group samples, the phosphorylation activity of nitric oxide synthase was investigated. Incubation was performed overnight at $4^{\circ} \mathrm{C}$ with the primary antibody (p-eNOS, 1/50, GeneTex) attached. After washing with phosphate-buffered saline, the secondary antibody (Histofine ${ }^{\circledR}$ Simple Stain MAX PO MULTI (Nichirei Bioscience Inc.)) was reacted for $1 \mathrm{~h}$. Finally, 3,3'-diaminobenzidine was added and allowed to react for $10 \mathrm{~min}$, before the samples were dehydrated, penetrated, and re-sealed.

The images of slides were obtained under the same conditions by using a microscope (BZ-X700; Keyence, Japan). The intensities of staining were quantified automatically on a scale of 1-255 with accompanied software.

\begin{tabular}{|lc|}
\hline Table 1. Patient Characteristics of Study Participants \\
Participants, $\mathrm{n}$ & 28 \\
Age, years & $71.9 \pm 6.7$ \\
Male sex, $\mathrm{n}(\%)$ & $20(71)$ \\
Hypertension, $\mathrm{n}(\%)$ & $20(71)$ \\
Hyperlipidemia, $\mathrm{n}(\%)$ & $20(71)$ \\
Diabetes mellitus, $\mathrm{n}(\%)$ & $8(29)$ \\
Smoking, $\mathrm{n}(\%)$ & $9(32)$ \\
BMl, kg/m² & $22.5 \pm 3.1$ \\
Cholesterol, mg/dL & $185.9 \pm 32.2$ \\
HDL, mg/dL & $52.2 \pm 14.4$ \\
Triglycerides, mg/dL* & $178.9 \pm 101.0$ \\
Medication, \% & \\
ACEi/ARBs & $9(32)$ \\
$\beta$-blockers & $11(39)$ \\
Aspirin/clopidogrel & $19(69)$ \\
Statins & $17(61)$ \\
CCBs & $12(43)$ \\
\hline
\end{tabular}

$\mathrm{ACEi}$, angiotensin-converting enzyme inhibitor; $\mathrm{ARB}$, angiotensin receptor blockers; BMI, body mass index; $\mathrm{CCB}$, calcium channel blockers; HDL, high-density lipoprotein. Values are expressed as mean \pm SEM, unless indicated otherwise. *Values expressed as median (25th-75th percentiles).

\section{Isometric Tension Measurement}

This study was performed with reference to previous research.22-25 After collection, the SVG tissue was divided into NT and CON groups, in vascular rings measuring $3 \mathrm{~mm}$ in length, and placed on a stainless-steel hook in an organ chamber containing $5 \mathrm{~mL}$ of Krebs-Henseleit solution at $37^{\circ} \mathrm{C}$ while blowing in Carbogen $\left(5 \% \mathrm{CO}_{2}\right.$ in $\left.\mathrm{O}_{2}\right)$. The blood vessel was set to a tension of $9.8 \mathrm{mN}$ and equilibrated for $\sim 30 \mathrm{~min}$. Tension was measured and recorded using a PowerLab recording system (AD Instruments, Oxfordshire, UK).

\section{Contractility of Smooth Muscle in SvGs}

After $30 \mathrm{~min}$ of equilibration, vasoconstriction response to $\mathrm{KCl}(30 \mathrm{mmol} / \mathrm{L})$ was measured. The $\mathrm{SVG}$ rings were washed out. Next, vasoconstriction response to L-phenylephrine (PE; $\left.10^{-5.5} \mathrm{~mol} / \mathrm{L}\right)$ was measured. The absolute value of contraction was obtained at the stable phase.

\section{Analysis of Endothelial-Dependent and -Independent Relaxation}

After stable contraction with PE $\left(10^{-5.5} \mathrm{~mol} / \mathrm{L}\right)$ was acquired, bradykinin (BK; $10^{-10}$ to $\left.10^{-5.5} \mathrm{~mol} / \mathrm{L}\right)$ was added for measuring endothelial-dependent relaxation. The involvement of nitric oxide (NO) for the relaxation was confirmed by adding a NO synthase inhibitor, NG nitroL-arginine methyl ester (L-NAME; $10^{-4} \mathrm{~mol} / \mathrm{L}, 30 \mathrm{~min}$ ), before contraction with $\mathrm{PE}$ or $\mathrm{KCl}$. Endothelial-independent relaxation was measured with nitroprusside (SNP; $10^{-10}$ to $10^{-5.5} \mathrm{~mol} / \mathrm{L}$ ) as a $\mathrm{NO}$ donor to vascular smooth muscle cells.

\section{Effects of PVAT-Derived Soluble Factors}

The effect of basal PVAT-derived soluble vasoactive factor was investigated by stably contracting NT and CON with phenylephrine $\left(10^{-5.5} \mathrm{~mol} / \mathrm{L}\right)$. The mediums of the NT group and CON group were exchanged half by half. The procedure made the PVAT-derived factor equivalent in the 


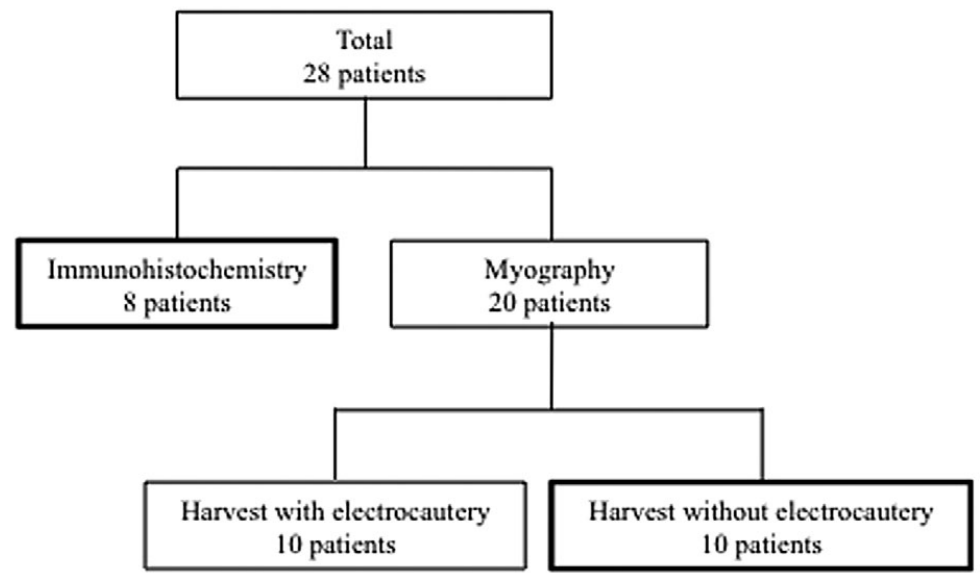

Figure 1. Flow chart of experimental procedures.
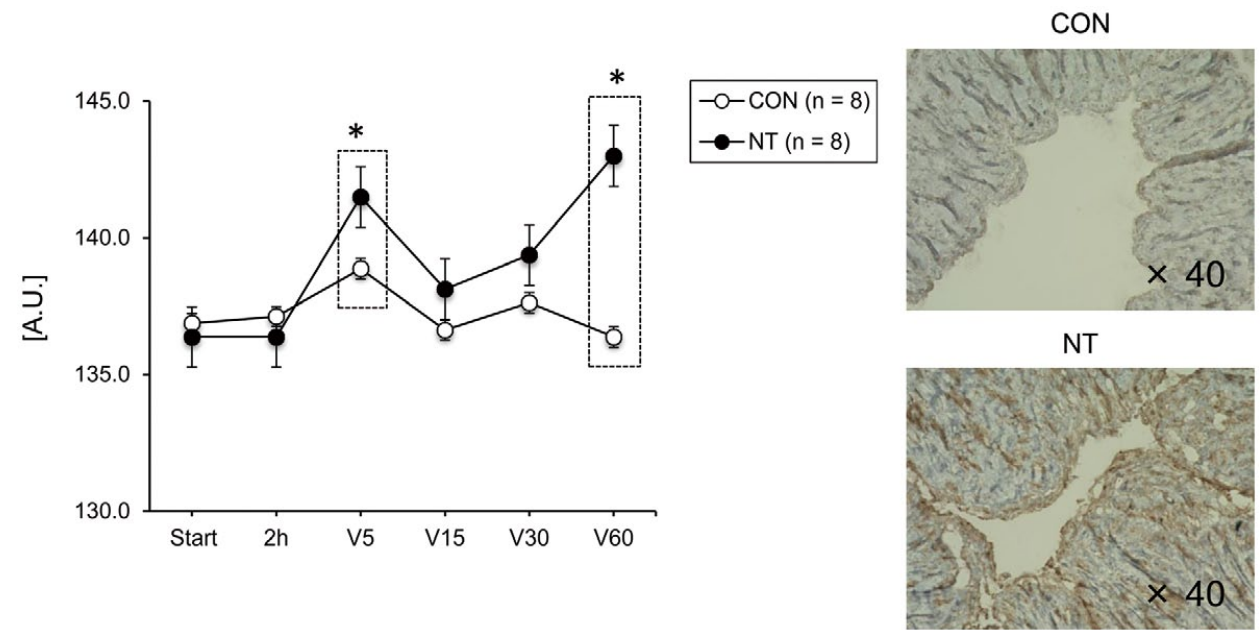

Figure 2. Immunohistochemistry using p-eNOS as the primary antibody; response to stimulation by vascular endothelial growth factor (VEGF) at the start: immediately after harvesting and fixing with formalin; and $2 \mathrm{~h}$ : after harvesting and rest for $2 \mathrm{~h}$ after fixation with formalin. V5-V60: react with VEGF for 5, 15,30, and $60 \mathrm{~min}$ and fixing with formalin. The density of the dye was evaluated in an arbitrary unit (AU) of 1-255 (1: thinnest, 255: darkest; Keyence BZ-X700 series). In response to stimulation by VEGF, the NT group was significantly better than the CON group at V5 and V60. ( $\left.{ }^{*}<<0.05\right)$. NT, no-touch technique; CON, conventional.

2 groups. After the mixture of mediums, changes in venous tone were observed for $30 \mathrm{~min}$.

\section{Statistics}

All experiments were performed in parallel on 2 segments taken from each vessel. Statistical analysis was performed by using SPSS (SPSS Inc., Chicago, IL, USA). Data are expressed as the mean and standard error of the mean. Differences in the IHC data were analyzed by using the Wilcoxon rank-sum test, whereas differences in myography data were analyzed using 2-way analysis of variance and Fisher's exact test. A P-value $<0.05$ was considered to be statistically significant. Maximum relaxation response is indicated as a percentage of the level before phenylephrineinduced contraction.

\section{Results}

\section{Patient Characteristics}

We initially recruited 28 patients between January 2017 and January 2018, mainly from Keio University Hospital and Sakakibara Heart Institute Hospital. Patient characteristics of study participants are shown in Table 1. The patients underwent selective CABG using a SVG and were chosen sequentially without setting any exclusion criteria. All tissue samples were collected using a NT technique. However, during the study, we noted that the samples, all of which were collected using electrocautery, showed a severely impaired response to any treatment, including $\mathrm{KCl}$, via a myograph. Therefore, SVGs taken by using electrocautery were excluded from the final analyses. Information on patient assignment is shown in Figure 1. 


\section{A NT (KCl: normal reaction)}

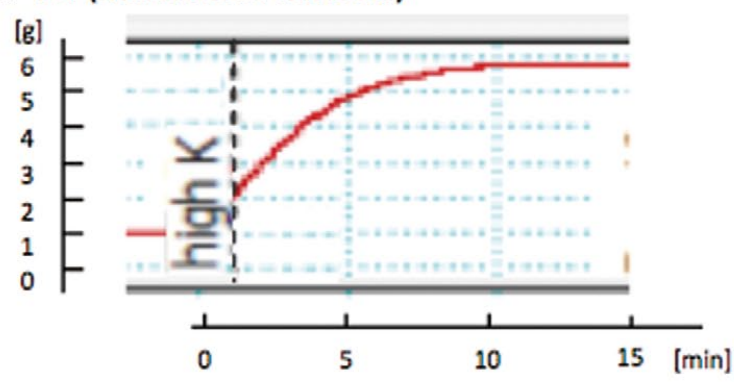

C NT (PE: normal reaction)

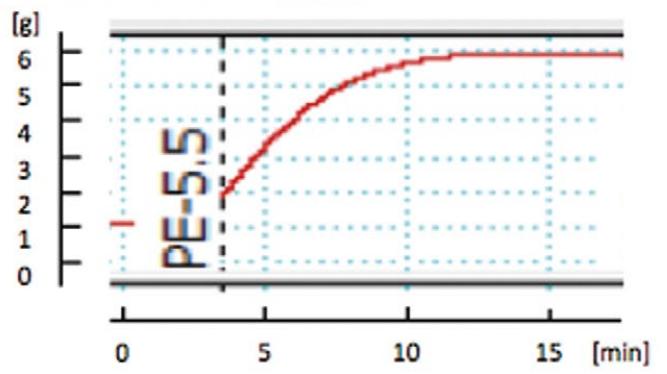

E NT (KCl: incompletely reaction)

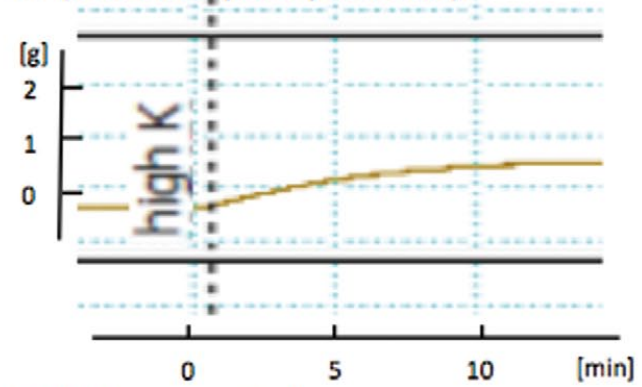

G NT (KCl: no reaction)

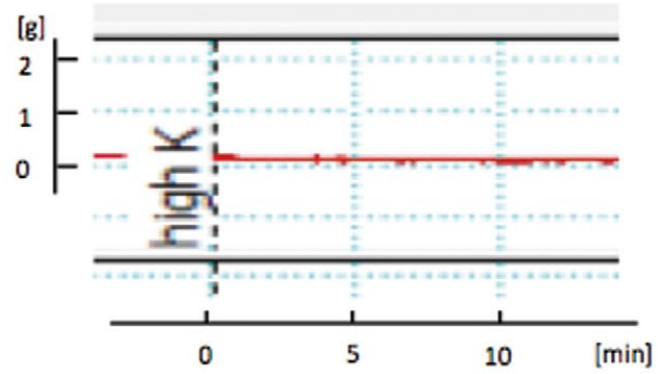

B CON (KCl: normal reaction)

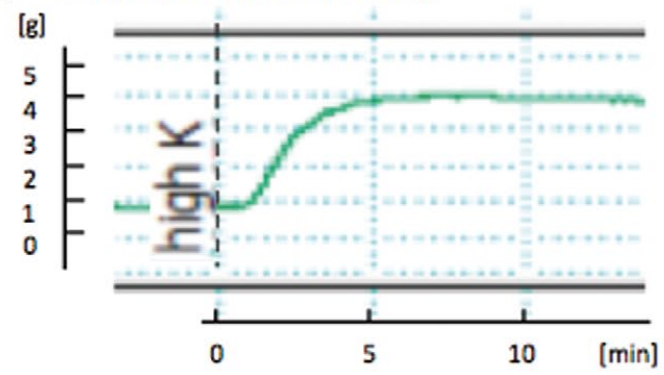

D CON (PE: normal reaction)

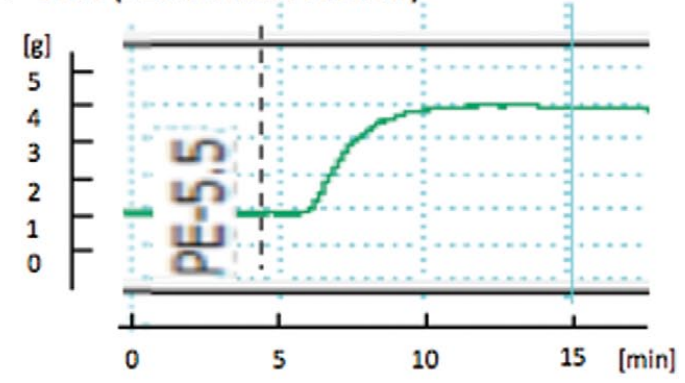

F NT (PE: incompletely reaction)
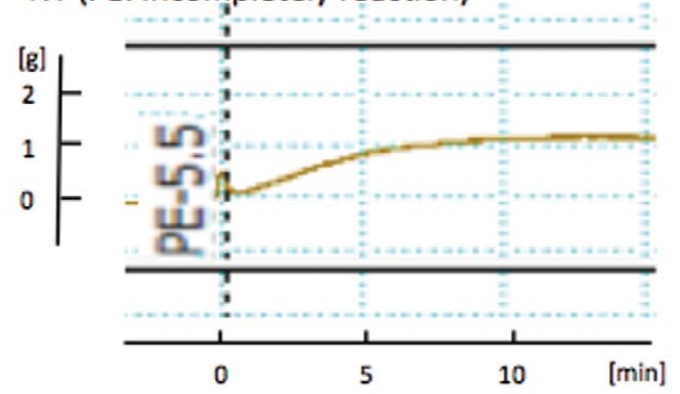

H NT (PE: no reaction)

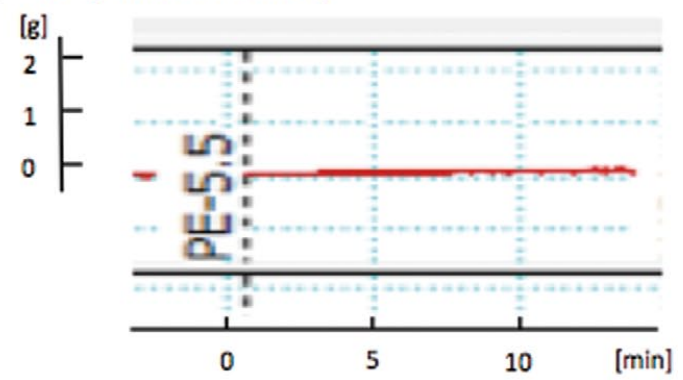

Figure 3. Contractive response of $\mathrm{KCl}$ and $\mathrm{PE}$ in myograph. (A-D) the comparison between $\mathrm{CON}$ and NT; (E-H) influence of collection of SVGs using electrocautery on drug reaction. Samples of (A-D) are from the same patient, in which electrocautery was not used. Samples (E-H) are from the same patient in which electrocautery was used with the NT technique. The contraction of SVGs taken of NT was stronger than CON; however, even when the NT technique was used, parts with no response and incomplete contraction existed in SVGs harvested using electrocautery. CON, conventional; NT, no-touch; PE, L-phenylephrine; SVG, saphenous vein graft. Abbreviations are as per Figure 2.

\section{Phosphorylation of eNOS by VEGF in IHC}

The phosphorylation of eNOS at Ser1177 by VEGF was significantly increased in the NT group than in the CON group at 5 and $60 \mathrm{~min}(\mathrm{~V} 5, \mathrm{P}=0.034 ; \mathrm{V} 60, \mathrm{P}=0.021)$ (Figure 2). The response by VEGF of total eNOS was not different between the NT and CON groups (Figure S2).

\section{Smooth Muscle Contractility With or Without PVAT in Myograph}

In all 20 cases, SVGs of 10 cases enrolled in this study were collected without using an electrocautery (Figure 1). In these cases, the contractile response to $\mathrm{KCl}$ and $\mathrm{PE}$ was significantly larger in the NT group than in the CON 
Table 2. Relationship Between Harvesting Method and Drug Response

\begin{tabular}{|llc} 
& \multicolumn{2}{c}{ Use of electrocautery } \\
\cline { 2 - 3 } Drug reaction & + & - \\
+ & & 10 \\
- & 4 & 0 \\
\hline
\end{tabular}

Among the 20 cases in which a myograph was performed, 10 cases were collected using electrocautery. Although these were excluded from this study, 6 out of 10 did not respond at all or responded incompletely to drug stimulation by $\mathrm{KCl}$ and $\mathrm{PE}$ $(P<0.05)$. We defined an "incomplete response" as a case of a mixture of good and bad reactions among samples from the same patient. An example of an incomplete response is in Supplemental Material. Furthermore, the absolute value of the contractile reaction of SVGs with PVAT collected with or without electrocautery is described below. There was no significant difference in each group (with electrocautery: $\mathrm{KCl}, 1.34 \pm 1.52$; PE, $1.52 \pm 1.46$; without electrocautery: $\mathrm{KCl}, 2.14 \pm 1.24 ; \mathrm{PE}, 2.21 \pm 1.07)$. PVAT, perivascular adipose tissue; PE, L-phenylephrine.

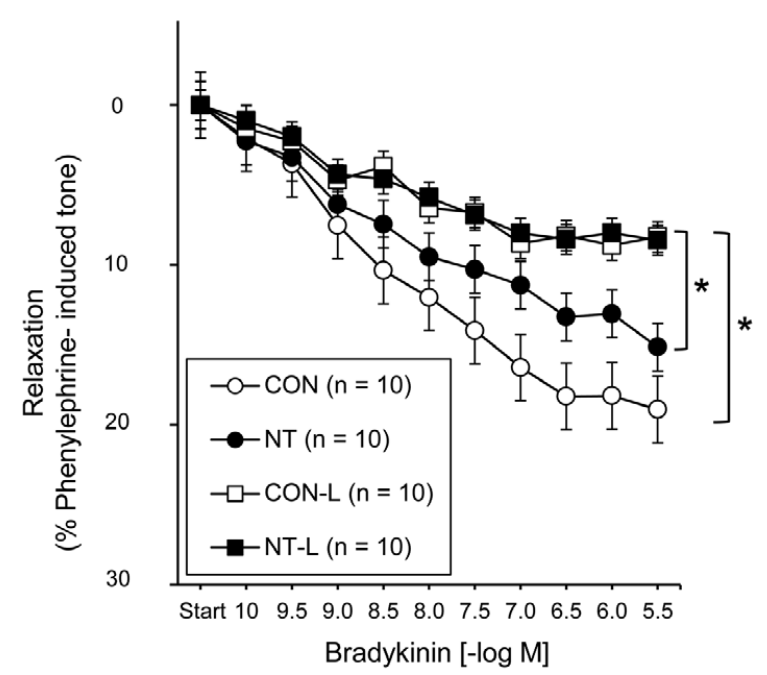

Figure 4. Vascular endothelium-derived relaxation reaction caused by bradykinin. Although pretreatment by phenylephrine was stronger in the NT group, vascular endothelium-derived relaxation caused by bradykinin was maintained by both NT and CON groups, both of which were inhibited by NG nitroL-arginine methyl ester (L-NAME). It was suggested that production of vascular endothelium-derived $\mathrm{NO}$ is equivalent to NT and CON. ${ }^{\star} P<0.05$. CON, conventional; NT, no-touch. Abbreviations are as per Figures 2,3.

group [KCl; NT: $2.08 \pm 0.91$ (g), CON: $1.36 \pm 0.91, \mathrm{P}<0.01$, PE; NT: $2.11 \pm 0.77, \mathrm{CON}$ : $1.37 \pm 0.67, \mathrm{P}<0.01]$ (Figure 3).

\section{Effect of Drug Reactivity by Electrocautery}

Although the SVGs were collected using the NT technique, samples that did not respond to drug stimulation existed. In the excluded 10 patients whose SVGs were collected using electrocautery, SVGs from 6 patients did not react at all. The SVGs from the rest of 4 patients responded incompletely to drug stimulation (Figure 3). The frequency of no or incomplete response is shown in Table 2. An image of an incomplete contraction is shown in the (Figure S3).

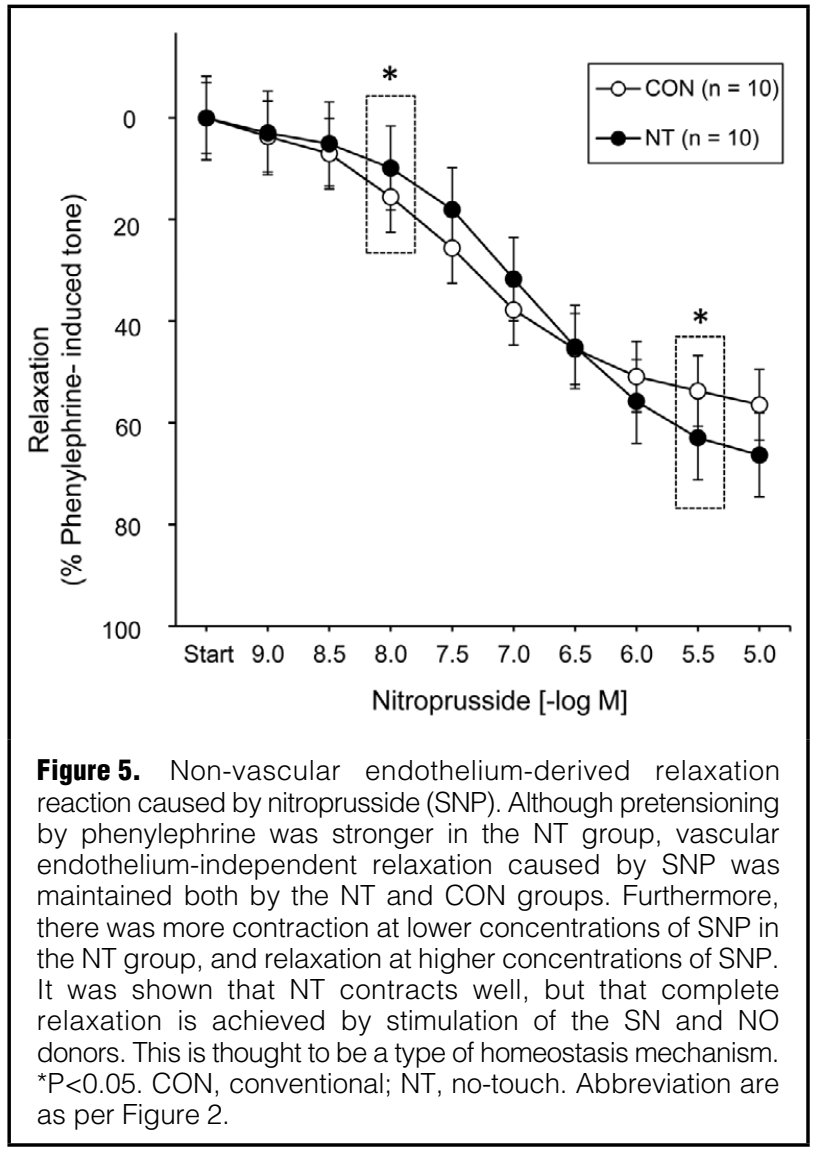

\section{Endothelial-Dependent Relaxation in Myograph}

The relaxation response to $\mathrm{BK}$ was used to investigate endothelial-dependent relaxation of SVGs. Response to BK was significantly decreased in the NT group than in the CON group $(\mathrm{P}<0.01)$. In the presence of L-NAME, the relaxation response to $\mathrm{BK}$ was markedly blunted and the response to $\mathrm{BK}$ was similar in both the NT and $\mathrm{CON}$ groups (Figure 4).

\section{Smooth Muscle Response to SNP}

Relaxations of SVGs to SNP was used to investigate endothelial-independent relaxation. The relaxation to NP in the NT group was smaller than that seen in the CON group at low concentrations $\left(10^{-8.0} \mathrm{~mol} / \mathrm{L} ; \mathrm{P}<0.05\right)$, and it was larger than that in the $\mathrm{CON}$ group at high concentrations $\left(10^{-5.5} \mathrm{~mol} / \mathrm{L} ; \mathrm{P}<0.05\right.$; Figure 5).

\section{Effect of Medium Exchange on Relaxation of SVGs as Detected by a Myograph}

The half exchange of medium induced relaxation in both the groups, and it was more prominent in the NT group at the earlier time point within $5 \mathrm{~min}(\mathrm{P}<0.05$; Figure 6).

\section{Discussion}

The data were summarized as follows. IHC showed that VEGF-induced eNOS phosphorylation at Ser1177 was increased in the NT group. As detected by using a myograph, smooth muscle contractile of SVGs was stronger in the NT group. However, the strong contraction was 
eliminated if SVGs were obtained by electrocautery. Smooth muscle relaxation in the NT group was reduced at low concentrations of SNP, but became greater than that observed in the $\mathrm{CON}$ group at high concentrations. Endothelium-dependent relaxation induced by BK was lower in the NT group. However, equalization of medium immediately restored relaxation in the NT group.

There are very few reports of applying myograph for SVGs so far. The strong vasoconstriction found in the NT group is concordant with results found in a previous study. ${ }^{13}$ However, our examinations further suggested the presence of PVAT-secreted vasoconstrictive factors. A high concentration of SNP might be the reason. We finally confirmed that SVGs from the NT group preserved both vasoconstriction and relaxation, although the experimental conditions such as dose of SNP and mediums varied.

Several mechanisms are speculated to be the reason for the preserved function of SVGs in the NT group. PVAT releases biologically active signaling molecules such as tumor necrosis factor- $\alpha,{ }^{14}$ hydrogen sulfide,${ }^{15} \mathrm{NO}$, adiponectin $^{16}$ and other adipocyte-induced relaxation factors. ${ }^{17-21}$ PVAT induces vascular relaxation and prevents spasm. Conversely, it was also reported that PVAT maintains vascular tone via superoxide, ${ }^{22}$ prostanoid ${ }^{23}$ and angiotensin II. ${ }^{24}$ In addition, autonomic vasomotor functions are relatively intact in SVGs with PVAT because perivascular nerves are distributed within PVAT. ${ }^{25,26}$ The sympathetic control with neurotransmitters, including noradrenaline, could be involved in the strong contraction. Therefore, in NT, it seems that micro blood vessels and nerves around SVGs are preserved, so reactivity and sensitivity to drugs may be preserved as compared with the CON group. Thus, PVAT could be protective for SVGs by keeping vascular homeostasis.

Another important factor is the decrease of perivascular damage in the NT group. In the present study, SVGs were not distended by high-pressure in either the NT or CON groups. However, the NT technique could further reduce injury of adventitia including vasa vasorum, ${ }^{27,28}$ and prevent inflammation, which provokes intimal hyperplasia. ${ }^{29}$ Additionally, we discovered SVGs from the NT group, which were collected using electrocautery, were not responsive in myograph. Heat injury was suspected despite a lack of difference in the appearance of SVGs. In this regard, further clinical and pathological studies are needed.

Taken together, vascular function of SVGs could be already varied before use. Our experiments suggested that the NT technique is superior to the CON technique in terms of both vasoconstriction and relaxation. We believe that our data would help to improve outcomes of CABG.

This study has several limitations. First, the clinical characteristics of patients were not considered in the study. However, the study subjects were identical in terms of having severe coronary atherosclerosis that required CABG. In addition, it is already known that PVAT changes function depending on the host site and properties. All patients had coronary artery disease, so it remains unknown whether their PVAT retained normal function. Second, a myograph found that untrimmed tissue surrounding the SVG ring containing PVAT may mechanically limit the vasodilation of the NT group. Furthermore, because the sample is immersed in solution, the influence of buoyancy should also be considered. However, we observed that the mixture of medium increased relaxation in the NT group in the contrary condition. Third, there is a difference in

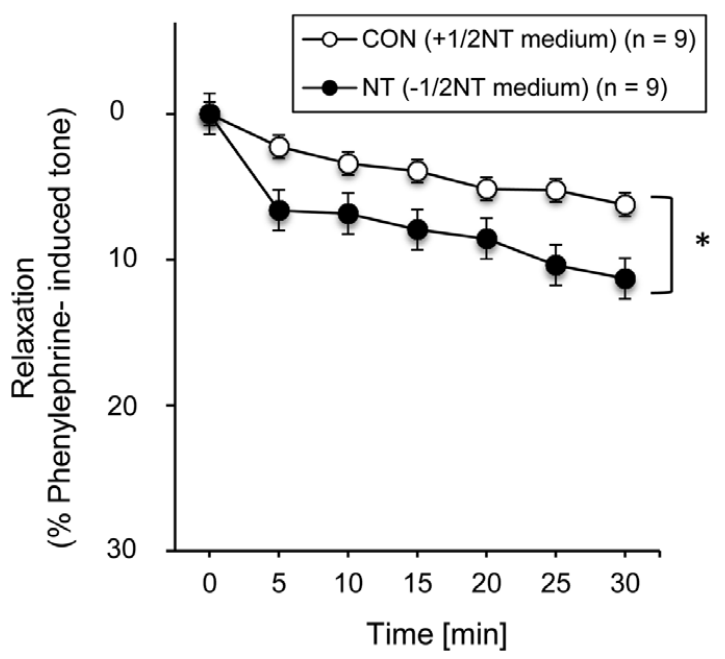

Figure 6. Effect of medium exchange on relaxation, as detected by a myograph. To examine the soluble vasoactive factor, the NT and CON group mediums were replaced by half after contraction with phenylephrine. As a result, the NT and CON media had equivalent properties. The CON group had a significantly weaker relaxation, suggesting that soluble vasoconstrictor factors produced in the NT group are involved. ${ }^{*} \mathrm{P}<0.05$. CON, conventional; NT, no-touch. Abbreviations are as per Figure 2 .

contractile force between the NT and CON groups, so it is difficult to purely examine the relaxation reaction. Finally, all myographs were performed $\sim 3 \mathrm{~h}$ after collection of SVGs. This is the timing that the specimens reached in laboratory. The time-course effects after removing PVAT were not evaluated in the study.

\section{Conclusions}

The NT technique is suggested to be advantageous for preserving the functions of vasoconstriction and relaxation. Also, it was suspected that PVAT maintains vascular tone by releasing vasoconstrictive factors.

\section{Acknowledgments}

The authors would like to thank T. Kimura, A. Sato, K. Ito and A. Osaki who belong to the National Defense Medical College and provided technical support and expertise for this experiment.

A grant from the Ministry of Defense, and a MEXT/JSPS KAKENHI Grant-in-Aid for Scientific Research (C: Number JP $17 \mathrm{~K} 09596$ and 17K09565) were received for this study.

\section{Disclosure}

The authors declare no conflicts of interest.

\section{References}

1. Favaloro RG. Saphenous vein graft in the surgical treatment of coronary artery disease: Operative technique. $J$ Thorac Cardiovasc Surg 1969; 58: $178-185$.

2. Dion R, Glineur D, Derouck D, Verhelst R, Noirhomme P, El Khoury $\mathrm{G}$, et al. Complementary saphenous grafting: Long-term follow-up. J Thorac Cardiovasc Surg 2001; 122: 296-304.

3. Cameron A, Davis KB, Green G, Schaff HV. Coronary bypass surgery with internal-thoracic-artery grafts: Effects on survival over a 15-year period. $N$ Engl J Med 1996; 334: 216-220.

4. Kim KB, Cho KR, Jeong DS. Midterm angiographic follow-up 
after off-pump coronary artery bypass: Serial comparison using early, 1-year, and 5-year postoperative angiograms. J Thorac Cardiovasc Surg 2008; 135: 300-307.

5. FitzGibbon GM, Kafka HP, Leach AJ, Keon WJ, Hooper GD, Burton JR. Coronary bypass graft fate and patient outcome: Angiographic follow-up of 5,065 grafts related to survival and reoperation in 1,388 patients during 25 years. $\mathrm{J} \mathrm{Am} \mathrm{Coll} \mathrm{Cardiol}$ 1996; 28: 616-626.

6. Khaleel MS, Dorheim TA, Duryee MJ, Durbin HE Jr, Bussey WD, Garvin RP, et al. High-pressure distention of the saphenous vein during preparation results in increased markers of inflammation: A potential mechanism for graft failure. Ann Thorac Surg 2012; 93: $552-558$

7. Souza D. A new "no-touch" preparation technique. Scand J Thorac Cardiovasc Surg 1996; 30: 41-44.

8. Verma S, Lovren F, Pan Y, Yanagawa B, Deb S, Karkhanis R, et al. Pedicled no-touch saphenous vein graft harvest limits vascular smooth muscle cell activation: The PATENT saphenous vein graft study. Eur J Cardiothorac Surg 2014; 45: 717-725.

9. Hwang HY, Kim MA, Seo JW, Kim KB. Endothelial preservation of the minimally manipulated saphenous vein composite graft: Histologic and immunohistochemical study. Thorac Cardiovasc Surg 2012; 144: 690-696.

10. Souza DS, Dashwood MR, Tsui JC, Filbey D, Bodin L, Johansson B, et al. Improved patency in vein grafts harvested with surrounding tissue: Results of a randomized study using three harvesting techniques. Ann Thorac Surg 2002; 73: 1189-1195.

11. Samano N, Geijer H, Bodin L, Arbeus M, Mannion JD, Dashwood M, et al. The no-touch saphenous vein graft in elderly coronary bypass patients with multiple comorbidities is a promising conduit to substitute the left internal thoracic artery. $J$ Thorac Cardiovasc Surg 2017; 154: 457-466.

12. Samano N, Geijer H, Liden M, Fremes S, Bodin L, Souza D. The no-touch saphenous vein for coronary artery bypass grafting maintains a patency, after 16 years, comparable to the left internal thoracic artery: A randomized trial. $J$ Thorac Cardiovasc Surg 2015; 150: $880-888$.

13. Vestergaard LP, Benhassen L, Modrau IS, de Paoli F, Boedtkjer E. Increased contractile function of human saphenous vein grafts harvested by "No-Touch" technique. Front Physiol 2018; 8: 1135.

14. Virdis A, Duranti E, Rossi C, Dell'Agnello U, Santini E, Anselmino M, et al. Tumour necrosis factor-alpha participates on the endothelin-1/nitric oxide imbalance in small arteries from obese patients: Role of perivascular adipose tissue. Eur Heart $J$ 2015; 36: 784-794.

15. Fang L, Zhao J, Chen Y, Ma T, Xu G, Tang C, et al. Hydrogen sulfide derived from periadventitial adipose tissue is a vasodilator. J Hypertens 2009; 27: 2174-2185.

16. Fortuno A, Rodriguez A, Gomez-Ambrosi J, Fruhbeck G, Diez J. Adipose tissue as an endocrine organ: Role of leptin and adiponectin in the pathogenesis of cardiovascular diseases. $J$ Physiol Biochem 2003; 59: 51-60.

17. Havel PJ. Update on adipocyte hormones: Regulation of energy balance and carbohydrate/lipid metabolism. Diabetes 2004; 53: S143-S151.

18. Thalmann S, Meier CA. Local adipose tissue depots as cardio- vascular risk factors. Cardiovasc Res 2007; 75: 690-701.

19. Yamawaki H, Tsubaki N, Mukohda M, Okada M, Hara Y Omentin, a novel adipokine, induces vasodilation in rat isolated blood vessels. Biochem Biophys Res Commun 2010; 393: 668-672.

20. Gao YJ, Lu C, Su LY, Sharma AM, Lee RM. Modulation of vascular function by perivascular adipose tissue: The role of endothelium and hydrogen peroxide. Br J Pharmacol 2007; 151: 323-331.

21. Lynch FM, Withers SB, Yao Z, Werner ME, Edwards G, Weston $\mathrm{AH}$, et al. Perivascular adipose tissue derived adiponectin activates $\mathrm{BKCa}$ channels to induce anticontractile responses. $\mathrm{Am}$ J Physiol Heart Circ Physiol 2013; 304: H786-H795.

22. Gao YJ, Takemori K, Su LY, An WS, Lu C, Sharma AM, et al. Perivascular adipose tissue promotes vasoconstriction: The role of superoxide anion. Cardiovasc Res 2006; 71: 363-373.

23. Ozen G, Topal G, Gomez I, Ghorreshi A, Boukais K, Benyahia $\mathrm{C}$, et al. Control of human vascular tone by prostanoids derived from perivascular adipose tissue. Prostaglandins Other Lipid Mediat 2013; 107: 13-17.

24. Lu C, Su LY, Lee RM, Gao YJ. Mechanisms for perivascular adipose tissue-mediated potentiation of vascular contraction to perivascular neuronal stimulation: The role of adipocyte-derived angiotensin II. Eur J Pharmacol 2010; 634: 107-112.

25. Loesch A, Dashwood MR. Nerve-perivascular fat communication as a potential influence on the performance of blood vessels used as coronary artery bypass grafts. J Cell Commun Signal 2018; 12: $181-191$.

26. Fernández-Alfonso MS, Gil-Ortega M, Aranguez I, Souza D, Dreifaldt M, Somoza B, et al. Role of PVAT in coronary atherosclerosis and vein graft patency: Friend or foe? Br J Pharmacol 2017; 174: $3561-3572$.

27. Dreifaldt M, Souza DS, Loesch A, Muddle JR, Karlsson MG, Filbey D, et al. The "no-touch" harvesting technique for vein grafts in coronary artery bypass surgery preserves intact vasa vasorum. $J$ Thorac Cardiovasc Surg 2011; 141: 145-150.

28. Dreifaldt M, Souza D, Bodin L, Shi-Wen X, Dooley A, Muddle $\mathrm{J}$, et al. The vasa vasorum and associated endothelial nitric oxide synthase is more important for saphenous vein than arterial bypass grafts. Angiology 2013; 64: 293-299.

29. de Vries MR, Quax PHA. Inflammation in vein graft disease. Front Cardiovasc Med 2018; 5: 3.

\section{Supplementary Files}

\section{Supplementary File 1}

Figure S1. All samples were taken with the no touch technique and used for actual surgery.

Figure S2. Immunohistochemistry using total-eNOS as the primary antibody; response to stimulation by VEGF.

Figure S3. An example of myograph of SVG was taken using an electrocautery.

Please find supplementary file(s);

http://dx.doi.org/10.1253/circj.CJ-18-0714 